\title{
The Research of the Effect of the Olive Juice on Anxiety and Depression Behavior
}

\author{
Jiguo Zhang*
}

Xi'an Jiaotong University, Xi'an, Shaanxi, P.R. China

\begin{abstract}
In order to evaluate the effect of olive juice on the anxiety and depression, the paper uses olive juice concentrate as the experimental material, and uses mice as the experimental subjects. Mice are randomly divided into negative, positive, high, medium and low-dose groups, administered orally for 7 days. Further, the impact of elevated plus maze test, the opening acts test and forced swim test was observed on the mice. The experimental results show that under conditions of the sub-acute administration, olive juice can not only induce anti-anxiety behavior in mice, but also has the potential to improve depression in mice.
\end{abstract}

Keywords: Anxiety, depression, olive juice.

\section{INTRODUCTION}

According to the World Health Organization, approximately 350 million people worldwide suffer from depression and other mood disorders. Affective disorder patients in China accounted for $6 \%$ of the population, the resulting direct and indirect economic losses amounted to 720 billion yuan annually $[3,7]$. As per current mainstream academic view, affective disorder is a syndrome. The pathogenesis involves multiple physiological systems, especially neurotransmitters and oxidative stress injury and so on [2].

At present, the clinical use of antidepressants play a role in the neurotransmitter system by slowing down the onset. Also, drugs have no synchronized effect [4], since there are large inter-individual differences in the drug response. Using components having antioxidant action to intervene the oxidative stress during affective disorder, is the idea of screening the affective disorder drug treatment.

Screening means animal anxiolytic and antidepressant drugs depend on a variety of classic behavioral experiments. Elevated plus maze test is widely used for evaluating characteristics of anxiolytic efficacy behavior in animal and effects of anxiety drugs. The ratio of residence times in the open arms and the number of entering the open arms of mice reflects the strength of their anxiety in the maze. The opening test is a method of evaluating anxiety behavior. When animals are in unfamiliar environments, behavioral strategies can be broken down into a safe area sports corner and open areas to the center of the movement [1]. The exercise time of central area negatively correlated with anxiety. Forced swim test is a classic antidepressant drug screening method. Time from motionless to react to the despair shows depressive behavior.

*Address correspondence to this author at the Xi'an Jiaotong University, Xi'an, Shaanxi, P.R. China; Tel: +358-6-3247476; Fax: +358-6-3247457; E-mail: hunter2011@foxmail.com
Olive belonging to the class Oleaceae, Olea, evergreen trees, is the world's leading oil producing fruit in woody species. Pharmacology studies found that olive contains a lot of polyphenols, especially oleanolic glycosides and hydroxytyrosol, at the level of animal, and in vitro studies showed levels of its antioxidant activity.

In order to assess whether the olive juice containing antioxidant substances has the efficacy of improving affective disorder, we used mice as research object, throughout the classic anti-anxiety and depression behavioral experiments. A study provides a reference for the use of olive juice to improve mood disorders [9].

The rest of the paper is organized as follows: In Section 2 , five kinds of classic test methods for depression and anxiety are described. In Section 3, the experimental materials, experimental procedures, and a method of analysis of experimental data are described. In Section 4, experiments are presented and the results are discussed. Finally, a conclusion is provided in Section 5.

\section{CLASSIC EXPERIMENTS DESCRIBED}

\subsection{Tail Suspension Test}

Tail suspension test detects the depression-like behavior in mice. After the mouse tail is wrapped with transparent tape, the tape ends with a clip-on, hang on a hook at a distance of at least $50 \mathrm{~cm}$ above the ground. Cameras record mice activity within 5 minutes. Statistically, there are two parameters of the incubation period in mice and the time motionless duration in mice [8-10].

\subsection{Open-Field Test}

Open-field test detects spontaneous activity and anxiety behavior of animals (McEwen, B. S. et al., 2005). Experimental equipment is a white square wooden box $(50 \mathrm{~cm} \times$ $50 \mathrm{~cm} \times 25 \mathrm{~cm}$ ) without a lid. A fixed right angle corner was selected. In each experiment, mice were placed on his back 
right angles [11]. After the boxes are turned into the mine, the operator immediately quits letting the mice freely move in the box for five minutes. Usually the residence time in the middle area and anxiety-like behavior are negatively correlated.

\subsection{Elevated Plus Maze}

Elevated plus maze is composed of two opposing open arms $(30 \mathrm{~cm} \times 5 \mathrm{~cm})$, two opposing closed arms $(30 \mathrm{~cm} \times 5$ $\mathrm{cm} \times 15 \mathrm{~cm})$ and a connecting four arm central platform $(5$ $\mathrm{cm} \times 5 \mathrm{~cm}$ ), $50 \mathrm{~cm}$ high from the ground (Claes, S, et al., 2004). Open arms light luminance is 650 Le, and light luminance of closed arm is 350 Le. Allowing animals to explore the new environment's characteristics, and overcoming the fear of hanging open arms, elevated plus maze reflects the animal anxiety forming a state of animal conflict. The time into the open arms and the number of residence time can be used to evaluate anxiety in animals. Elevated plus maze is thus the sum of the open arms and closed arms and the number of times in the central area of the probe to evaluate the animal motor activity and exploration capabilities. During the test, each mouse was placed in the center of the platform for $5 \mathrm{~min}$ to record the times into the open arms and closed arms and number of the residence time, by entering the sum of number of the open arms and closed arms, and the probe frequency in the central region. Enter any of the four legs of mice where arm in arm are into the inner prevail. Foot exit from the arm into the activities deemed complete.

\subsection{Forced Swimming Test}

Forced swim detects major depression-like behavior in mice and affect their motor function [6]. In a high $20-25 \mathrm{~cm}$ diameter cylindrical transparent container containing water at temperature around $25^{\circ} \mathrm{C}$, mice was placed at his back to the wall of the container, by gently letting go after the front foot contacts the water. The first time the mice adapt to swimming in 10 minutes that is, not recorded to swim for 10 minutes. The next record is six minutes of swimming activity in mice in the container. When finished, the animal was taken out, dried with a dry towel and put back to squirrel cage. Statistically, there are two parameters of the time i.e. motionless time and the latency time.

\subsection{Sugar Preference Experiments}

Sugar preference experimental mice were evaluated on the basis of the proportion of drink syrup and anhedonia in mouse. Mice in depression generally lose preference for sugar. After the mice were deprived of water for 24 hours while giving autoclaved water to make $1 \%$ sucrose and autoclaved sterile water, after 24 hours they were let to drink freely, then timely weighed to calculate the ratio of the amount of sugar water to the total amount of water.

\section{EXPERIMENTAL PROCEDURE}

\subsection{Experimental Materials}

Experiments use healthy adult male Sprague Dawley, whose weights are 200-240g. After the mice acclimatized (temperature $20-24^{\circ} \mathrm{C}$, humidity of $55 \%-60 \%$ ) for 10 hours, the 20 rats were randomly divided into two groups, control group (fed tap water) and experimental group (fed olive) .

\subsection{Experimental Methods}

\subsubsection{Open-Field Test}

A fixed right angle corner was selected. For each experiment, mice were placed at their back right angles. After the boxes are converted into the mine, the operator immediately quits, letting free mouse activity in the box for five minutes.

\subsubsection{Elevated Plus Maze}

During the test, each mouse was placed in the center of the platform for $5 \mathrm{~min}$ to record the times into the open arms and closed arms and number of the residence time, by entering the sum of number of the open arms and closed arms, and the probe frequency in the central region. Enter any of the four legs of mice where arm in arm are into the inner prevail. Foot exit from the arm into the activities deemed complete.

\subsubsection{Forced Swimming Test}

The first time the mice adapt to swimming in 10 minutes that is, not recorded to swim for 10 minutes. The next record is six minutes of swimming activity in mice in the container. When finished, the animal was taken out, dried with a dry towel and put back to squirrel cage. Statistically, there are two parameters of the time i.e. motionless time and the latency time.

\subsection{Data Statistics Methods}

Variance is a measure of the degree of deviation between random variables and its mathematical expectation (i.e. mean). In many practical settings, studying the degree of deviation between random variables and mean is of great significance.

$$
D(\mathrm{X})=\mathrm{E}\left(\mathrm{X}^{2}\right)-[\mathrm{E}(\mathrm{X})]^{2}
$$

Variance can also has the below form:

$$
s^{2}=\frac{1}{n}\left[\left(\mathrm{x}_{1}-\mathrm{x}\right)^{2}+\left(\mathrm{x}_{2}-\mathrm{x}\right)^{2}+\ldots+\left(\mathrm{x}_{n}-\mathrm{x}\right)^{2}\right]
$$

The analysis of variance can be used as an exploratory tool to explain observations. A dog show provides such an example. A dog show is not a random sampling of the breed: it is typically limited to dogs that are male, adult, pure-bred, and exemplary. A histogram of dog weights from a show might plausibly be rather complex, like the yellow-orange distribution shown in the illustrations. Suppose we wanted to predict the weight of a dog based on a certain set of characteristics of each dog. Before we could do that, we would need to explain the distribution of weights by dividing the dog population into groups based on those characteristics. A successful grouping will split dogs such that (a) each group has a low variance of dog weights (meaning the group is relatively homogeneous) and (b) the mean of each group is distinct (if two groups have the same mean, then it isn't reasonable to conclude that the groups are, in fact, separate in any meaningful way). 
In probability and statistics, the most commonly used is the statistical distribution to measure the degree of statistical dispersion. It reflects the degree of dispersion among the individuals within a group.

In probability and statistics, a probability distribution assigns a probability to each measurable subset of the possible outcomes of a random experiment, survey, or procedure of statistical inference. Examples are found in experiments whose sample space is non-numerical, where the distribution would be a categorical distribution; such as, experiments whose sample space is encoded by discrete random variables, where the distribution can be specified by a probability mass function; and experiments with sample spaces encoded by continuous random variables, where the distribution can be specified by a probability density function. More complex experiments, such as those involving stochastic processes defined in continuous time, may demand the use of more general probability measures.

\section{ANALYSIS OF EXPERIMENTAL RESULTS}

First, the field test is conducted. Based on the total distance movement (Fig. 1) and velocity (Fig. 2), it has been observed that Olive juice fed mice and normal mice have the same self-activity. There are however, some differences, but they are insignificant. The residence time in the central region of the mines (Fig. 3) was not significantly different, indicating no significant difference between the two groups' anxiety-like behavior.

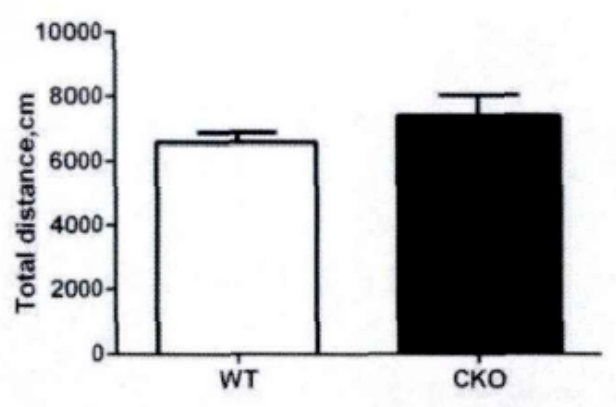

Fig. (1). The total motor distance of the mice in the field test.

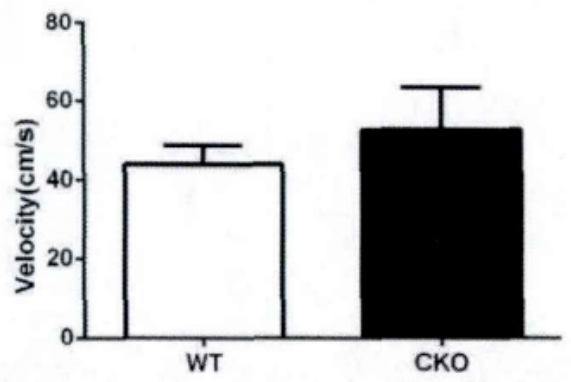

Fig. (2). The speed of movement of the mice in the field test.

In field test, the residence time in center area triggers anxiety, while the total movement distance triggers motor function in mice. Our experimental results show that the juice will not significantly increase locomotor activity dis- tance in mice, i.e. the effect of Juice on anxiety in mice is weak, and there is no significant central nervous stimulation.

High plus maze is a classic model to measure anxiety in mice. According to the mice in the open arms of the plus maze, high residence time see Fig. (4) evaluates the anxiety. There are some differences between experimental mice and control mice with respect to the residence time in the open arms and the number of times into the open arms (Fig. 5). This shows that the olive juice has some anti-anxiety effects.

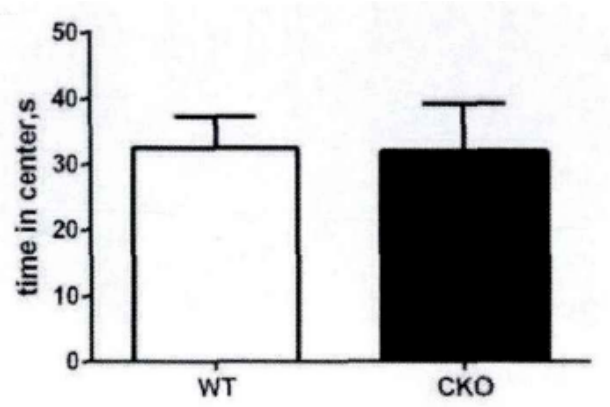

Fig. (3). The motorless time of the mice in the center area in the field test.

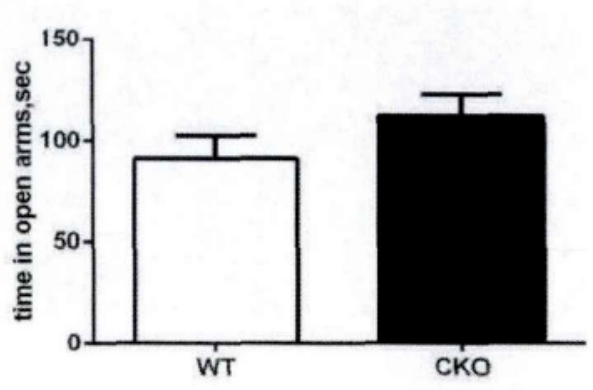

Fig. (4). The residence time in high plus-maze open arms.

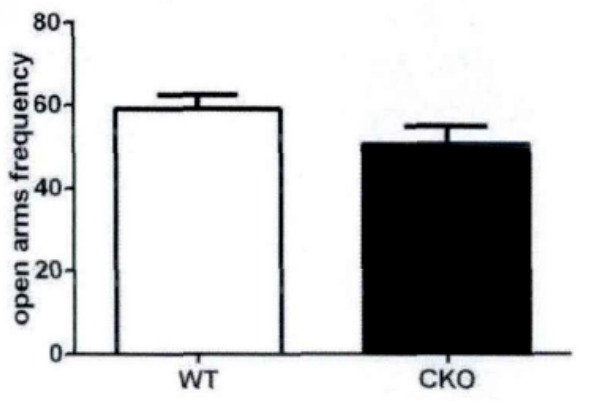

Fig. (5). The residence time in the open arms and the times into the open arms.

Forced swim test results are shown in Table 1. The juice at three doses decreased the motionless time of mice, but that is not statistically significant. This motorless state shows a desperate behaviour, which the antidepressants in the forced swim test can significantly reduce.

Experimental results show that the olive juice given in the current dose, cannot significantly reduce motionless behavior in mice, which exhibits its antidepressant effects. 
Table 1. The unmoving time of forced swimming tests in mice.

\begin{tabular}{|c|c|c|c|}
\hline Group & $\begin{array}{c}\text { Low-dose } \\
\text { administered } \\
\text { group (3g/kg) }\end{array}$ & $\begin{array}{c}\text { Middle-dose } \\
\text { administered } \\
\text { group (7g/kg) }\end{array}$ & $\begin{array}{c}\text { High-dose } \\
\text { administered } \\
\text { group (12g/kg) }\end{array}$ \\
\hline \hline $\begin{array}{c}\text { Unmoving time } \\
\text { (s) }\end{array}$ & 86 & 98 & 92 \\
\hline
\end{tabular}

\section{CONCLUSION}

The experimental results show that under conditions of sub-acute administration, olive juice not only induces antianxiety behavior in mice, but also has the potential to improve depression [5]. Individual experimental results show that the difference in behaviour between experimental and control groups, did not reach statistical significance levels; this is probably due to that the amount of olive juice is not very reasonable.

\section{CONFLICT OF INTEREST}

The authors confirm that this article content has no conflict of interest.

\section{ACKNOWLEDGEMENTS}

This work is supported by the Key Project of Guangxi Social Sciences, China (No. gxsk201424), the Education Science fund of the Education Department of Guangxi, China (No. 2014JGA268), and Guangxi Office for Education Sciences Planning, China (No. 2013C108).

\section{REFERENCES}

[1] D. Bleakman, A. Alt and J. M. Witkin, "AMP A receptors in the therapeutic management of depression", CNS Neurol. Disord. Drug Targets, vol. 6, no. 2, pp. 117-126, 2007.

[2] S. Chourbaji, M. A. Vogt, F. Fumagalli, R. Sohr, A. Frasca, C Brandwein, H. Hörtnagl, M. A. Riva, R. Sprengel and P. Gass, "AMPA receptor subunit 1 (GIuR-A) knockout mice model the glutamate hypothesis of depression", FASEB J., vol. 22, no. 9, pp. 3129-3134, 2008.

[3] S. J. Claes, "CRH, stress, and major depression: A psychobiological interplay", Vitam Horm, vol. 69, pp. 117-50, 2004

[4] F. Holsboer, A. Gerken, G. K. Stalla and O. A. Müller, "ACTH, Cortisol, and corticosterone output after ovine corticotrophinreleasing factor challenge during depression and after recovery", Biol. Psychiatry, ,vol. 20, no. 3, pp. 276-86, 1985.

[5] M. Ising, H. E. Künzel, E. B. Binder, T. Nickel, S. Modell and F Holsboer, "The combined dexamethasone/CRH test as a potential surrogate marker in depression", Prog. Neuropsychopharmacol. Biol. Psychiatry, vol. 29, no. 6, pp. 1085-93, 2005.

[6] L. A. Jans, W. J. Riedel, C. R. Markus and A. Blokland, "Serotonergic vulnerability and depression: Assumptions, experimental evidence and implications", Mol. Psychiatry, vol. 12, no. 6, pp. 522-43, 2007.

[7] S. A. Johnson, N. M. Foumier and L. E. Kalynchuk, "Effect of different doses of corticosterone on depression-like behavior and HPA axis responses to a novel stressor", Behav. Brain Res., vol. 168 , no. 2, pp. $280-288,2006$

[8] H. W. Kessels and R. Malinow, "Synaptic AMP A receptor plasticity and behaviour", Neuron, vol. 61, no. 3, pp. 340-350, 2009.

[9] S. Maeng, C. J. Zarate, J. Du, R. J. Schloesser, J. McCammon, G. Chen and H. K. Manji, "Cellular mechanisms underlying the antidepressant effects of ketamine; role of alpha-amino-3-hydroxy-5methylisoxazole-4-propionic acid receptors", Biol. Psychiatry, vol 63, no. 4, pp. 349-352, 2008

[10] S. Meltzer-Brody, A. Stuebe, N. Dole, D. Savitz, D. Rubinow and J. Thorp, "Elevated corticotrophin releasing hormone (CRH) during pregnancy and risk of postpartum depression (PPD)", J. Clin. Endocrinol. Metab., vol. 96, no.1, pp. 40-47, 2011.

[11] B. S. McEwen, "Glucocorticoids, depression, and mood disorders: Structural remodeling in the brain", Metabolism, vol. 54, no. 5, pp. 20-23, 2005 .

Received: May 26, 2015

(C) Jiguo Zhang; Licensee Bentham Open.

This is an open access article licensed under the terms of the (https://creativecommons.org/licenses/by/4.0/legalcode), which permits unrestricted, noncommercial use, distribution and reproduction in any medium, provided the work is properly cited. 